\title{
Tip 2 Diyabetli Hastalarda Dapagliflozin Tedavisinin Trombosit Fonksiyonları ve İnflamasyon Üzerine Etkisi
}

\author{
Mehmet Ali EREN ${ }^{1}$, Çiğdem CÍNDOĞLU ${ }^{2}$, Burcu DİKEÇ GÖKÇE ${ }^{2}$, Ali GÖKÇE ${ }^{2}$, \\ Tevfik SABUNCU ${ }^{1}$
}

1 Harran Üniversitesi Tıp Fakültesi, Endokrinoloji Bilim Dalı, Şanlıurfa, Türkiye.

2 Harran Üniversitesi Tıp Fakültesi, İç Hastalıkları Ana Bilim Dalı, Şanlıurfa, Türkiye.

\section{ÖZET}

Dapagliflozin kardiyovasküler hastalıklarda güvenli ve yararlı olduğu gösterilen bir oral anti-diyabetik (OAD) ilaçtır. Dapagliflozinin kardiyovasküler olumlu etkilerinin kesin mekanizması tam olarak bilinmemektedir. Bu çalışmada, dapagliflozin kullanan hastalarda tedavinin trombosit fonksiyonunu gösteren ortalama trombosit hacmi (OTH) ve yeni inflamatuar belirteçler olan nötrofil lenfosit oranı (NLO) ve trombosit lenfosit oranı (TLO) üzerine etkilerini araştırmayı amaçladık. Daha önce OAD veya OAD+insülin tedavisi almakta iken tedaviye dapagliflozin eklenen, 18 yaş üstü tip 2 diyabeti olan hastaların dosyaları incelenerek, dapagliflozin tedavisi başlamadan önce ve tedaviden sonra 3-6 ay içindeki laboratuar verileri kaydedildi. Dapagliflozin tedavisi ile birlikte glukoz ve A1c değerleri anlamlı olarak azalırken (her iki $\mathrm{p}<0.001$ ), hemoglobin, hematokrit ve NLO değerleri anlamlı olarak arttı (sırasıyla $\mathrm{p}=0.005, \mathrm{p}=0.001$ ve $\mathrm{p}=0.032$ ). Ayrıca nötrofil sayısı anlamlı olarak artarken, lenfosit sayısı anlamlı olarak azaldı $(\mathrm{p}=0.029$ ve $\mathrm{p}=0.019)$. Dapagliflozin etkili bir OAD olup vücuttaki inflamasyon üzerine etkileri bulunmaktadır. Bu etkinin nasıl ve neden olduğunun anlaşılmasına ihtiyaç vardır.

Anahtar Kelimeler: Dapagliflozin. Ortalama Trombosit Hacmi. Nötrofil Lenfosit Oranı. Trombosit Lenfosit Oranı.

The Effect of Dapagliflozin on Platelet Function and Inflammation in Type 2 Diabetes

\begin{abstract}
Dapagliflozin is an oral anti-diabetic drug (OAD) that has been shown to be safe and useful in cardiovascular diseases. The exact mechanism of cardiovascular positive effects of dapagiflozin is not fully understood. In this study, we aimed to investigate the effects of dapagliflozin treatment on mean platelet volume (MPV) as the marker of platelet function, and neutrophil lymphocyte ratio (NLR) and platelet lymphocyte ratio (PLR) as new anti-inflammatory markers. Laboratory data were recorded before and 3-6 months after the treatment of patients with type 2 diabetes over age of 18 years who received dapagliflozin when receiving OAD or OAD + insulin. Glucose and A1c values were significantly decreased (both $\mathrm{p}<0.001$ ) and hemoglobin, hematocrit and NLR values were significantly increased with dapagliflozin treatment ( $\mathrm{p}=0.005, \mathrm{p}=0.001$ and $\mathrm{p}=0.032$, respectively). In addition, neutrophil count increased significantly and lymphocyte count decreased significantly ( $\mathrm{p}=0.029$ and $\mathrm{p}=0.019$ ). Dapagliflozin is an effective OAD and affects inflammation in the body. There is a need to understand how and why this effect occurs.
\end{abstract}

Key Words: Dapagliflozin. Mean Platelet Volume. Neutrophil Lymphocyte Ratio. Platelet Lymphocyte Ratio.

Tip 2 diyabetes mellitus (T2DM), ilerleyici bir hastalıktır ve hastada glisemik kontrolün sürdürülebilmesi için zamanla tedavinin yoğunlaştırılması gerekmektedir. Hedeflenen glisemik değerlere ulaşabilmek için çoğu zaman birden fazla ilacın kombine edilmesine ihtiyaç olmaktadır.

Geliş Tarihi: 05 Eylül 2019

Kabul Tarihi: 18 Ekim 2019

Dr. Mehmet Ali EREN

Harran Üniversitesi Tıp Fakültesi,

İç Hastalıkları Anabilim Dalı,

Endokrinoloji Bilim Dalı,

Osmanbey Kampüsü, ŞANLIURFA

TIf: 05324363127

e-posta: drmalieren@hotmail.com
Güncel k1lavuzlar, T2DM tedavisine metformin ile başlamayı, ikinci bir ilaç gerektiğinde ise hasta bazlı düşünerek ilaç eklemeyi önermektedirler ${ }^{1-3}$. Son zamanlarda, sodyum-glukoz ko-transporter 2 (SGLT-2) inhibitörleri T2DM tedavisinde kullanıma girmiş olan bir anti-diyabetik ilaç grubudur. Glukoz düzeyini düşürmesinin yanı sıra kilo kaybına ve kan basıncı kontrolüne de olumlu etkileri bulunmaktadir ${ }^{4,5}$.

Ortalama trombosit hacmi (OTH), trombositlerin ortalama büyüklüğünü gösteren bir hematolojik değerdir. Büyük trombositlerin küçük olanlara göre metabolik ve enzimatik olarak daha aktif ve daha yüksek hemostaz özelliğine sahip olduğu gösterilmiş$\operatorname{tir}^{6,7}$. Nötrofil lenfosit oranı (NLO) ve trombosit lenfosit oranı (TLO) ise son yıllarda ucuz ve kolay bir yöntem olarak çeşitli kardiyak ve kardiyak olmayan du- 
rumlarda kullanılmaya başlanan yeni inflamatuar belirteçlerdir ${ }^{8-11}$.

Bir SGLT-2 inhibitörü olan dapagliflozinin kardiyovasküler ölüm veya kalp yetmezliği nedeniyle hastaneye yatış ve kardiyovasküler olay riskinde azalma gibi kardiyak olaylar üzerine olumlu etkileri olduğu gösterilmiştir $^{12,13}$. Ancak bu olumlu etkilerin hangi mekanizmalar ile meydana geldiği tam olarak bilinmemektedir. Çalışmamızda, dapagliflozin tedavisi öncesi ve sonrası OTH, NLO ve TLO düzeylerine bakarak bu tedavinin platelet fonksiyonları ve inflamasyon üzerine olan etkilerini ortaya çıkarmayı amaçladik.

\section{Gereç ve Yöntem}

Endokrinoloji polikliniğinde en az bir yıldır takip edilmekte olan ve çeșitli oral antidiyabetik ilaç (OAD) veya $\mathrm{OAD}+$ insülin tedavisi almakta iken, kan şekeri regülasyonu sağlanamadığı için tedaviye dapagliflozin eklenen hastaların dosyaları incelendi. 18 yaş üstü tip 2 diyabeti olan hastaların, dapagliflozin tedavisi başlamadan önce ve tedaviden sonra 3-6 ay içindeki laboratuar verileri kaydedildi. Bilinen malignitesi, akut enfeksiyonu, gebelik durumu, romatolojik hastalığı ve aşikar organ yetmezliği olan hastalar çalışma dışı bırakıldı. Toplam 55 hasta çalışmaya dahil edildi. Çalışma protokolü lokal etik kurulu tarafindan onaylandi.

Tedavi öncesi ve sonrası bakılan kan sayımı değerlerinden, nötrofil sayısının lenfosit sayısına bölünmesi ile NLO, trombosit sayısının lenfosit sayısına bölünmesi ile TLO değerleri hesap edildi.

\section{İstatistiksel Analiz}

Veriler ortalama \pm standart deviasyon olarak belirtildi. Verilerin dağılımının normal olup olmadığı Kolmogorov-Smirnov testi ile değerlendirildi. Normal dağılan veriler için Bağımlı Gruplarda T Testi, normal dağılım göstermeyen veriler için Wilcoxon İşaretli Sıra Testi kullanıldı. İstatistiksel analizler SPSS 20.0 sürümü ile yapıldı. P değerinin $0.05^{\prime}$ 'in altında olması anlamlı kabul edildi.

\section{Bulgular}

Hastaların yaş ortalamaları $55.5 \pm 7.9$ (35-75) yıl idi. Hastaların dapagliflozin tedavisi sonrası ortalama glukoz (212.7 $\pm 77.6 \mathrm{mg} / \mathrm{dL}$ 'den $177.1 \pm 61.8 \mathrm{mg} / \mathrm{dl}$ 'ye) ve ortalama A1c $(\% 9.4 \pm 2.0$ 'dan $8.3 \pm 1.5$ 'e) değerleri anlamlı olarak azaldı (her iki $\mathrm{p}<0.001$ ). Tedavi sonrası ortalama hemoglobin $(14.0 \pm 1.8 \mathrm{~g} / \mathrm{dL}$ 'den $14.4 \pm 1.8$ g/dL'ye) ve hematokrit (\%44.3 \pm 4.6 'dan \% $45.9 \pm 4.2$ 'ye) değerleri anlamlı olarak arttı (sırasıyla $\mathrm{p}=0.005$ ve $\mathrm{p}=0.001$ ). Dapagliflozin tedavisi ile NLO
(1.8 \pm 0.7 'den $2.3 \pm 1.7^{\prime}$ ye) ve nötrofil say1s1 $\left(5.0 \pm 1.5 \times 10^{9} / \mathrm{L}\right.$ 'den $5.6 \pm 2.0 \times 10^{9} / \mathrm{L}$ 'ye) anlamlı olarak artarken (sırasiyla $p=0.029$ ve $p=0.032$ ), lenfosit sayıs1 (3.0 $\pm 0.8 \times 10^{9} / \mathrm{L}$ 'den $2.8 \pm 0.9 \times 10^{9} / \mathrm{L}$ 'ye) anlamlı olarak azaldı $(\mathrm{p}=0.019)$. Trombosit sayısı ve OTH değerlerinde tedavi sonucu anlamlı değişiklik saptanmadı. Tüm bu veriler Tablo I’de gösterildi.

Tablo I. Dapagliflozin tedavisinin kan biyokimyası ve sayımı üzerine etkileri

\begin{tabular}{|l|c|c|c|}
\hline Parametre & Tedavi öncesi & Tedavi sonrası & $\mathbf{p}$ \\
\hline Glukoz (mg/dL) & $212.7 \pm 77.6$ & $177.1 \pm 61.8$ & $<0.001$ \\
\hline A1c (\%) & $9.4 \pm 2.0$ & $8.3 \pm 1.5$ & $<0.001$ \\
\hline Kreatinin (mg/dL) & $0.8 \pm 0.1$ & $0.8 \pm 0.2$ & 0.235 \\
\hline Lökosit (10\%/L) & $8.9 \pm 2.0$ & $9.3 \pm 2.4$ & 0.098 \\
\hline Nötrofil (10\%/L) & $5.0 \pm 1.5$ & $5.6 \pm 2.0$ & 0.029 \\
\hline Lenfosit (10\%/L) & $3.0 \pm 0.8$ & $2.8 \pm 0.9$ & 0.019 \\
\hline Hemoglobin (g/dL) & $14.0 \pm 1.8$ & $14.4 \pm 1.8$ & 0.005 \\
\hline Hematokrit (\%) & $44.3 \pm 4.6$ & $45.9 \pm 4.2$ & 0.001 \\
\hline Trombosit (10//L) & $287.3 \pm 73.0$ & $285.8 \pm 90.3$ & 0.861 \\
\hline NLO & $1.8 \pm 0.7$ & $2.3 \pm 1.7$ & 0.032 \\
\hline TLO & $103.4 \pm 32.4$ & $109.4 \pm 43.6$ & 0.099 \\
\hline OTH (fL) & $8.1 \pm 1.3$ & $8.0 \pm 1.3$ & 0.437 \\
\hline
\end{tabular}

\section{Tartışma ve Sonuç}

Aterosklerotik kalp damar hastalıkları (ASKDH), diyabetli hastalarda hayat kalitesini ve iş yaşamını bozan, tıbbi bakım maliyetini arttıran morbiditelere yol açmakta ve bu kişilerin üçte ikisinin ölüm nedeni olmaktadır $^{14}$. Diyabeti olmayan birine kiyasla diyabetli kişilerde ASKDH riski yaklaşık 2 kat $\operatorname{artmıştır~}^{15}$. Bu nedenle diyabet tedavisinin esas hedeflerinden biri ASKDH'ın önlenmesidir.

Ateroskleroz endotel hücrelerde hasar ile başlayıp, inflamasyonun eklenmesi ile birlikte atrosklerotik plakların ve trombozun oluşumuna kadar ilerleyen bir süreçtir $^{16-18}$. Li ve ark., dapagliflozinin in vitro olarak trombosit agregasyonunu bozarak anti-platelet etkisi olduğunu göstermişlerdir ${ }^{19}$. Diabetes mellitus, hipertansiyon, dislipidemi, obezite, akut miyokard infarktüsü ve akut iskemik stroke aterosklerotik durumlarda daha aktif trombosit varlığını gösteren artmış OTH düzeyleri saptanmıştır ${ }^{20,21}$. Diyabeti olan hastalarda dapagliflozinin OTH üzerine etkisini gösteren literatürde herhangi bir çalışma bulunmamaktadır. Bizim çalışmamızda, dapagliflozinin trombosit sayısı ve hacmi üzerine anlamlı etkisi olmadığı görüldü.

NLO'nun, ucuz, yeni ve kullanışlı bir inflamatuar belirteç olarak, ASKDH'da hastalığın şiddeti ve prognozu ile ilişkili olduğu bildirilmiştir ${ }^{22,23}$. Prediyabet ve diyabet durumlarında NLO seviyelerinin arttığı, artmış NLO düzeylerinin diyabetik hastalarda subklinik ve aşikar ASKDH ile ilişkili olduğu belirlenmiştir ${ }^{24-26}$. Benzer şekilde ucuz ve yeni bir inflamasyon belirteci olan TLO, ASKDH varlığı ve şiddeti ile ilişkili bu- 


\section{Dapagliflozin, Trombosit Fonksiyonları ve İnflamasyon}

lunmuştur $^{27,28}$. Prediyabetik ve diyabetik bireylerde TLO düzeyinin diyabetik olmayanlara göre arttı̆̆ ayrıca miyokard infarktüsü geçiren diyabetiklerde kötü prognoz belirteci olduğu gösterilmiştir ${ }^{24,29}$. Fareler üzerinde yapılan çalışmalarda, dapagliflozinin böbrek, kalp ve beyinde inflamasyon üzerine olumlu etkileri olduğu bulunmuştur ${ }^{30-32}$. Díaz-Rodríguez ve arkadaşları in vitro ortamda dapagliflozinin epikardiyal yağ dokusunda inflamatuar sitokinlerin azalmasına yol açtığını göstermişlerdir ${ }^{33}$. Solini ve arkadaşları ise T2DM2si olan hastalarda, dapagliflozin tedavisinin akut dönemde endotelyal fonksiyon ve arteryel sertlik üzerine olumlu etkileri olduğunu göstermişlerdir ${ }^{34}$. Ancak diyabetik hastalarda dapagliflozin tedavisinin inflamatuar belirteçler üzerine nasıl bir etkisi olduğunu gösteren çalışma mevcut değildir. Çalışmamızda TLO değerinde farklılık saptanmazken, NLO ve nötrofil sayısının arttığını, lenfosit sayısının azaldığını tespit ettik. Bulgularımız dapagliflozin tedavisinin ilk defa gerçek diyabetik hastalarda inflamasyon üzerine etkisi olduğunu göstermiştir. Ancak bu durumun olumlu veya olumsuz yansımaları ile ilgili karar vermek çalışmamızın amacı değildir. Retrospektif dizayn, sınırlı hasta sayısı, hastaların ASKDH düzeylerinin tam bilinmemesi, inflamasyonun yüksek sensitif Creaktif protein, interlökin-6 gibi daha genel-geçer belirteçler ile değerlendirilmemiş olması bu konuda karar vermeyi zorlaştıran durumlardır ve aynı zamanda çalışmamızın sınırlılıklarıdır. Ayrıca retrospektif dizayn nedeniyle inflamatuar süreci ve dolayısıyla NLO'yu etkileyebilecek diğer hastalıkların gözden kaçma ihtimali de çalışmanın bir diğer sınırlayıcı faktörüdür.

Çalışmamızın bir diğer bulgusu, hemoglobin ve hematokrit düzeylerinde görülen artıştır. SGLT-2 inhibitörlerinin hemokonsantrasyon yaptıkları bilinmektedir. Bu durumun böbrek tübüllerindeki ve interstiyumundaki stressin azalmasına ve sempatik hiperaktivitenin düzelmesiyle ilişkili olabileceği bildirilmiştir ${ }^{35}$.

Sonuç olarak, dapagliflozin hipergliseminin düzeltilmesinde etkili bir oral antidiyabetik ilaç olmasının yanı sıra kan hücrelerinin sayısında ve oranlarında değişikliklere yol açabilmektedir. Bu durum dapagliflozinin T2DM'si olan hastalarda inflamatuar belirteçlerde değişiklik yapabildiğini göstermektedir. Ancak bu değişimin neden ve nasıl olduğuna yönelik ileri çalışmalara gerek vardır.

\section{Kaynaklar}

1. American Diabetes Association. 8. Pharmacologic Approaches to Glycemic Treatment: Standards of Medical Care in Diabetes2018. Diabetes Care 2018;41(Suppl 1):73-85.

2. Davies MJ, D'Alessio DA, Fradkin J, et al. Management of hyperglycaemia in type 2 diabetes, 2018. A consensus report by the American Diabetes Association (ADA) and the European Association for the Study of Diabetes (EASD). Diabetologia 2018;61(12):2461-98.
3. Lipscombe L, Booth G, Butalia S, et al. Pharmacologic Glycemic Management of Type 2 Diabetes in Adults. Diabetes Canada Clinical Practice Guidelines Expert Committee. Can J Diabetes 2018;42(1):88-103.

4. Bailey CJ, Gross JL, Hennicken D, Iqbal N, Mansfield TA, List JF. Dapagliflozin add-on to metformin in type 2 diabetes inadequately controlled with metformin: a randomized, doubleblind, placebo- controlled 102-week trial. BMC Med 2013;11:43.

5. Plosker GL. Dapagliflozin: a review of its use in patients with type 2 diabetes. Drugs 2014;74(18):2191-209.

6. Bath PM, Butterworth RJ. Platelet size: measurement, physiology and vascular disease. Blood Coagul Fibrinolysis 1996;7(2):157-61.

7. Martin JF, Trowbridge EA, Salmon G, Plumb J. The biological significance of platelet volume: its relationship to bleeding time, platelet thromboxane B2 production and megakaryocyte nuclear DNA concentration. Thromb Res 1983;32(5):443-60.

8. Verdoia M, Schaffer A, Barbieri L, et al. Impact of diabetes on neutrophil-to-lymphocyte ratio and its relationship to coronary artery disease. Diabetes Metab 2015;41(4):304-11.

9. Imtiaz F, Shafique K, Mirza SS, Ayoob Z, Vart P, Rao S. Neutrophil lymphocyte ratio as a measure of systemic inflammation in prevalent chronic diseases in Asian population. Int Arch Med 2012;5:2.

10. Li W, Liu Q, Tang Y. Platelet to lymphocyte ratio in the prediction of adverse outcomes after acute coronary syndrome: a meta-analysis. Sci Rep 2017;7:40426.

11. Atak B, Aktas G, Duman TT, Erkus E, Kocak MZ, Savli H. Diabetes control could through platelet-to-lymphocyte ratio in hemograms. Rev Assoc Med Bras (1992) 2019;65(1):38-42.

12. Persson F, Nyström T, Jørgensen ME, et al. Dapagliflozin is associated with lower risk of cardiovascular events and allcause mortality in people with type 2 diabetes (CVD-REAL Nordic) when compared with dipeptidyl peptidase-4 inhibitor therapy: A multinational observational study. Diabetes Obes Metab 2018;20(2):344-51.

13. Wiviott SD, Raz I, Bonaca MP, et al. Dapagliflozin and Cardiovascular Outcomes in Type 2 Diabetes. N Engl J Med 2019;380(4):347-57.

14. Low Wang CC, Hess CN, Hiatt WR, Goldfine AB. Clinical Update: Cardiovascular Disease in Diabetes Mellitus: Atherosclerotic Cardiovascular Disease and Heart Failure in Type 2 Diabetes Mellitus - Mechanisms, Management, and Clinical Considerations. Circulation 2016;133(24):2459-2502.

15. Ferrannini E, DeFronzo RA. Impact of glucose-lowering drugs on cardiovascular disease in type 2 diabetes. Eur Heart J 2015;36:2288-2296.

16. Santos-Gallego CG, Picatoste B, Badimon JJ. Pathophysiology of acute coronary syndrome, Curr Atheroscler Rep 2014;16:9.

17. Projahn D, Koenen RR. Platelets: key players in vascular inflammation, J Leukoc Bio 2012;92:1167-75.

18. de Maat MP, Bladbjerg EM, Drivsholm T, Borch-Johnsen K, Møller L, Jespersen J. Inflammation, thrombosis and atherosclerosis: results of the Glostrup study. J Thromb Haemost 2003;1(5):950-7.

19. Li Z, Xu X, Deng L, et al. Design, synthesis and biological evaluation of nitric oxide releasing derivatives of dapagliflozin as potential anti-diabetic and anti-thrombotic agents. Bioorg Med Chem 2018;26(14):3947-52.

20. Vizioli L, Muscari S, Muscari A. The relationship of mean platelet volume with the risk and prognosis of cardiovascular diseases. Int J Clin Pract 2009;63:1509-15.

21. Bayram SM, Gürsoy G, Araz Güngör A, Güngör F, Atalay E. The relationship of mean platelet volume with microalbuminuriain type 2 diabetic patients. Turk J Med Sci 2016;46(2):251-8. 


\section{M.A. Eren, ark.}

22. Kaya H, Ertaş F, İslamoğlu Y, et al. Association between neutrophil to lymphocyte ratio and severity of coronary artery disease. Clin Appl Thromb Hemost 2014;20(1):50-4.

23. Zuin M, Rigatelli G, Picariello C, et al. Correlation and prognostic role of neutrophil to lymphocyte ratio and SYNTAX score in patients with acute myocardial infarction treated with percutaneous coronary intervention: A six-year experience. Cardiovasc Revasc Med 2017;18(8):565-71.

24. Mertoglu C, Gunay M. Neutrophil-Lymphocyte ratio and Platelet-Lymphocyte ratio as useful predictive markers of prediabetes and diabetes mellitus. Diabetes Metab Syndr 2017;11(1):127-31.

25. Li X, Shen J, Lu Z, Chen M, Fang X, Wang G. High neutrophil-to-lymphocyte ratio is associated with increased carotid artery intima-media thickness in type 2 diabetes. J Diabetes Investig 2017;8(1):101-107.

26. DiGangi C. Neutrophil-lymphocyte ratio: Predicting cardiovascular and renal complications in patients with diabetes. J Am Assoc Nurse Pract 2016;28(8):410-4.

27. Balta S, Ozturk C.The platelet-lymphocyte ratio: A simple, inexpensive and rapid prognostic marker for cardiovascular events. Platelets 2015;26(7):680-1.

28. Akboga MK, Canpolat U, Yayla C, et al. Association of Platelet to Lymphocyte Ratio With Inflammation and Severity of Coronary Atherosclerosis in Patients With Stable Coronary Artery Disease. Angiology 2016;67(1):89-95.

29. Hudzik B, Szkodzinski J, Gorol J, et al. Platelet-to-lymphocyte ratio is a marker of poor prognosis in patients with diabetes mellitus and ST-elevation myocardial infarction. Biomark Med 2015;9(3):199-207.
30. Jaikumkao, K, Pongchaidecha, A, Chueakula, N, et al. Dapagliflozin, a sodium-glucose co-transporter-2 inhibitor, slows the progression of renal complications through the suppression of renal inflammation, endoplasmic reticulum stress and apoptosis in prediabetic rats. Diabetes Obes Metab. 2018;20:261726

31. Ye Y, Bajaj M, Yang HC, Perez-Polo JR, Birnbaum Y. SGLT2 Inhibition with Dapagliflozin Reduces the Activation of the Nlrp3/ASC Inflammasome and Attenuates the Development of Diabetic Cardiomyopathy in Mice with Type 2 Diabetes. Further Augmentation of the Effects with Saxagliptin, a DPP4 Inhibitor. Cardiovasc Drugs Ther 2017;31(2):119-32.

32. Sa-Nguanmoo P, Tanajak P, Kerdphoo S,et al. SGLT2-inhibitor and DPP-4 inhibitor improve brain function via attenuating mitochondrial dysfunction, insulin resistance, inflammation, and apoptosis in HFD-induced obese rats. Toxicol Appl Pharmacol. 2017;333:43-50.

33. Díaz-Rodríguez E, Agra RM, Fernández ÁL, Adrio B, GarcíaCaballero T, González-Juanatey JR, Eiras S. Effects of dapagliflozin on human epicardial adipose tissue: modulation of insulin resistance, inflammatory chemokine production, and differentiation ability. Cardiovasc Res 2018;114(2):336-46.

34. Solini A, Giannini L, Seghieri M, et al. Dapagliflozin acutely improves endothelial dysfunction, reduces aortic stiffness and renal resistive index in type 2 diabetic patients: a pilot study. Cardiovasc Diabetol 2017;16(1):138.

35. Sano M, Goto S. Possible Mechanism of Hematocrit Elevation by Sodium Glucose Cotransporter 2 Inhibitors and Associated Beneficial Renal and Cardiovascular Effects. Circulation. 2019;139(17):1985-7. 